\title{
A Study of a Darrieus Vertical Axis Wind Turbine with a guiding nozzle
}

\author{
"Valentin Obretenov ${ }^{1, *}$ and Rossen Iliev ${ }^{1}$ \\ ${ }^{1}$ Tehnical University of Sofia, Department of Hydroaerodynamics and Hydraulic Machinery, Bulgaria
}

\begin{abstract}
This paper presents the results from an experimental study of a Vertical Axis Wind turbine model with a guiding nozzle. The geometry of the nozzle is synthesized by an original methodology. The performance characteristics of the turbine are investigated when changing the number of the blades and their pitch angle. The obtained results allow us to generate generalized characteristics that can be used in the design of new turbines of this type. The results of the pilot studies showing higher efficiency than the classical Darrieus wind turbines (up to $50 \%$ which is close to the Betz limit).
\end{abstract}

\section{Introduction}

The idea of using a guiding nozzle in a Darrieus vertical axis wind turbine (VAWT) is not new. For example in [1] a study for such a type of turbine is presented, in which no energy efficiency indicators were determined due to the limited capabilities of the used stand. There have been publications from other researchers who have used additional devices e.g. flow accelerators spanning the entire perimeter of the runner [2], or local guiding nozzles [2-4], etc.

Studies made at the Laboratory of Hydropower and Hydraulic Turbomachinery at the Technical University Sofia [5] have shown that the use of a nozzle type of a guidance device increases the values of the tip speed ratio - TSR (compared to the design without a guidance device). A major drawback of this study is the inability to determine the energy performance of the turbine. Furthermore, the interaction of the nozzle with the blades has not been investigated which is an important condition for achieving high efficiency [6].

The paper presents the results of research aimed at increasing the efficiency of the workflow of a VAWT Darrieus by optimizing the interaction of the guidance device and the runner.

\footnotetext{
*Corresponding author: v_obretenov@tu-sofia.bg
} 


\section{Description of the experiment}

\subsection{Guiding apparatus (nozzle)}

A special methodology and a computer program for calculation of the guide apparatus for cross-flow water turbine were used for the sizing of the guide nozzle [6]. This methodology has proven the efficient operation of dozens of small hydropower plants over many years. Fig. 1 shows a computer model and a drawing (cross section) of the nozzle and the runner. The active nozzle angle is $\delta=90^{\circ}$. The nozzle geometry (both sides 1a and 1b) besides the acceleration of the workflow (as it is in similar designs $[2,3]$ ), also provides a constant value of the angle of attack if the runner's blades $\left(\alpha_{0}=15^{\circ}\right)$ within the active angle $\delta$. This is an important condition in terms of ensuring compliance and the most essential requirement is to provide approximately equal values of the flow angles in the two sections, i.e. $\alpha_{0}=\alpha_{1}$ (Fig.1). The nozzle height is $\mathrm{B}_{\mathrm{d}}=960 \mathrm{~mm}$, and the values of the important geometric parameters L1, L2 и L3 are 1200, 430 и $1200 \mathrm{~mm}$.
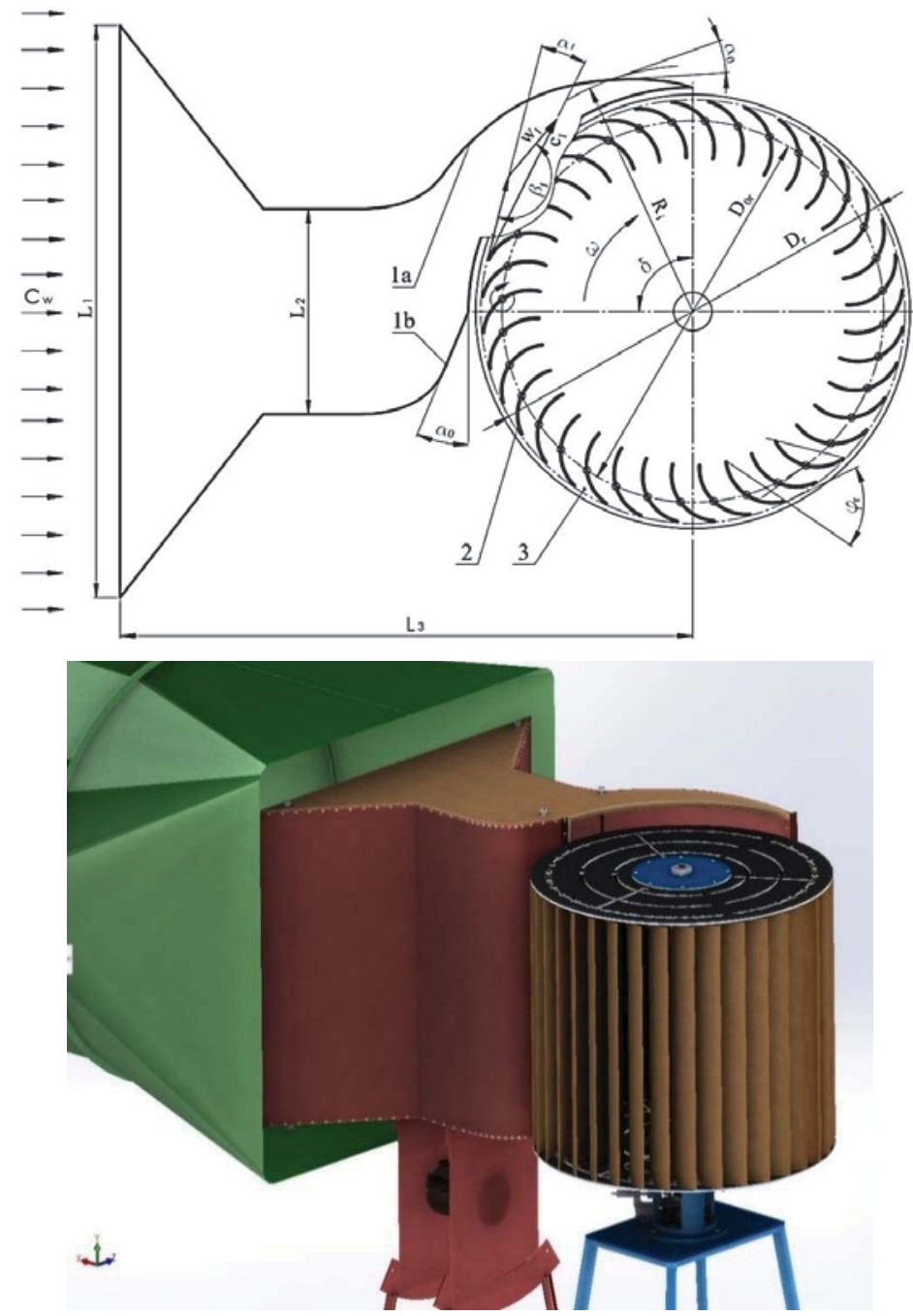

Fig. 1. Nozzle and Runner. 


\subsection{Runner}

The running blades 2 (Fig.1) are mounted between two disks 3, their axis lying on a cylindrical surface with diameter $\mathrm{D}_{0} \mathrm{r}=800 \mathrm{~mm}$. The blades can be rotated around their axis in order to change their pitch angle $\varphi_{\mathrm{r}}(\mathrm{deg})$. In each of the supporting disks, grooves of three circles were made, which enabled the instalment of different number of working blades (up to $\mathrm{Z}_{\mathrm{r}}=48$ ) on three different diameters [5].

The runner and the nozzle are mounted on two independent platforms, the runner being placed inside an aerodynamic tunnel. A general view of the model block with two different runners is shown in Fig.2 (a: $\left.Z_{\mathrm{r}}=6 ; \mathbf{b}: Z_{\mathrm{r}}=36\right)$.

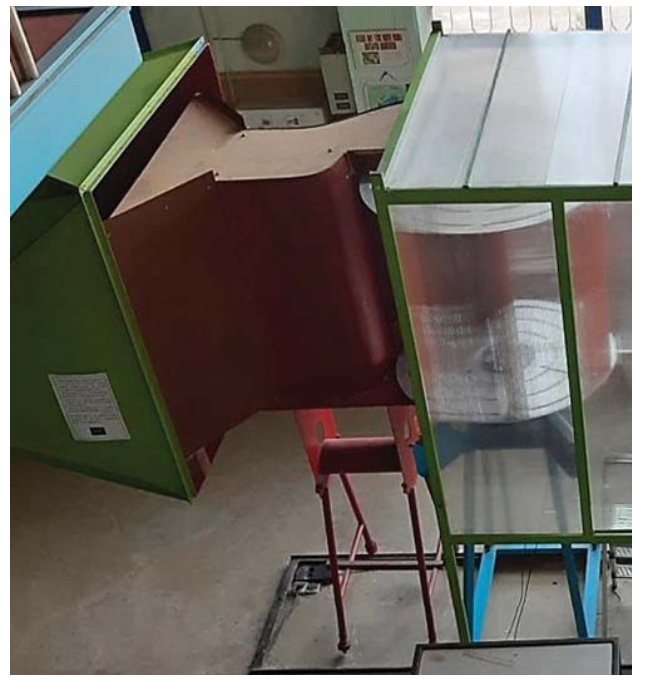

a.

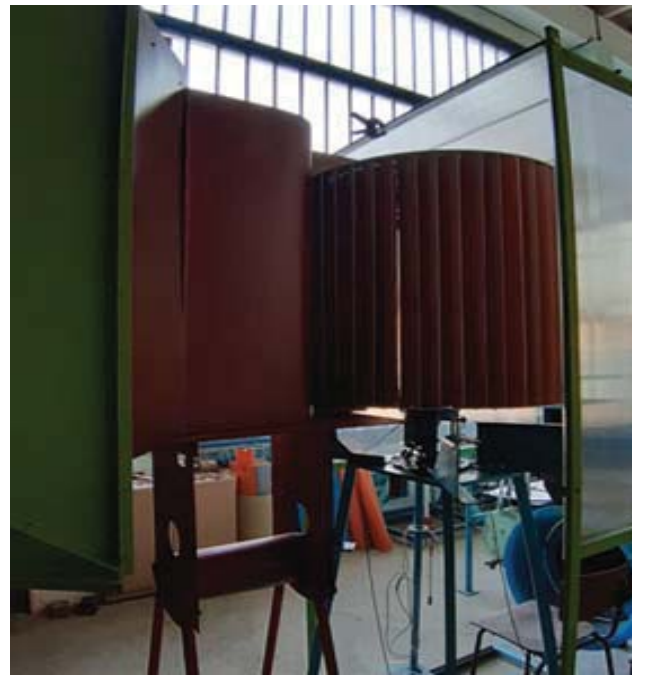

b.

Fig. 2. Model block

The study was made with several values of the pitch angle $\varphi_{\mathrm{r}}=40^{\circ}, 50^{\circ}, 55^{\circ}, 60^{\circ}, 70^{\circ}$, with number of blades: $Z_{\mathrm{r}}=6,12,24,36$ and 48. The purpose is to construct the generalized dependence $c_{\mathrm{p} \text { max }}=\mathrm{f}\left(\varphi_{\mathrm{r}}, \mathrm{Z}_{\mathrm{r}}\right)$. The methodology for constructing a model of water turbines with universal characteristics [7] is used. At each point in the experiment plan, the load on the turbine shaft is changed and the maximum value $\left(c_{p \max }\right)$ of the power coefficient $c_{p}$ is determined.

\section{Measured quantities}

The power coefficient $c_{p}$ is defined as the ratio between the rotor output power and the dynamic power of the air [9]:

$$
\begin{gathered}
c_{p}=\frac{P}{P_{w}} \\
P=M_{b} \cdot \omega=M_{b} \cdot \frac{\pi \cdot n}{30} \\
P_{w}=\rho \cdot S \cdot \frac{C_{W, S}^{3}}{2}
\end{gathered}
$$

In equation (1) $\mathrm{P}$ is the effective power (on the shaft) of the turbine, and $\mathrm{P}_{\mathrm{w}}$ is the power of the air flow, W. In equations (2) и (3) $M_{b}$ is the torque, N.m; $n$ - speed of rotation, 
$\mathrm{rpm}, \mathrm{c}_{\mathrm{w}, \mathrm{s}}-$ average wind velocity, $\mathrm{m} / \mathrm{s}, \mathrm{S}=\mathrm{L}_{1} . \mathrm{B}$ - inlet section of the guiding nozzle, $\mathrm{m}^{2}$ (Fig.1). The experiments were made with a constant value of the wind's velocity: $\mathrm{c}_{\mathrm{w}, \mathrm{s}}=5.9$ $\mathrm{m} / \mathrm{s}$.

For each experiment the so-called tip speed ratio TSR[8] was used, which is the ratio of the peripheral velocity $u$ in the outermost section of the runner to the wind velocity:

$$
T S R=\frac{u}{c_{w}}
$$

The experiments were made on stand №7C in the Laboratory of Hydropower and Hydraulic Turbomachinery at the Technical University of Sofia - HEHT [5,8].

\section{Results}

The results of the experimental study allow us to construct generalized characteristic $c_{\mathrm{pmax}}=\mathrm{f}\left(\varphi_{\mathrm{r}}, \mathrm{Z}_{\mathrm{r}}\right)$ (an analogue of the model universal characteristics for water turbines [5]). Fig. 3 shows the performance characteristics $c_{p}=f(T S R)$ for four points of the experimental plan, and Fig.4 shows the generalized characteristic.

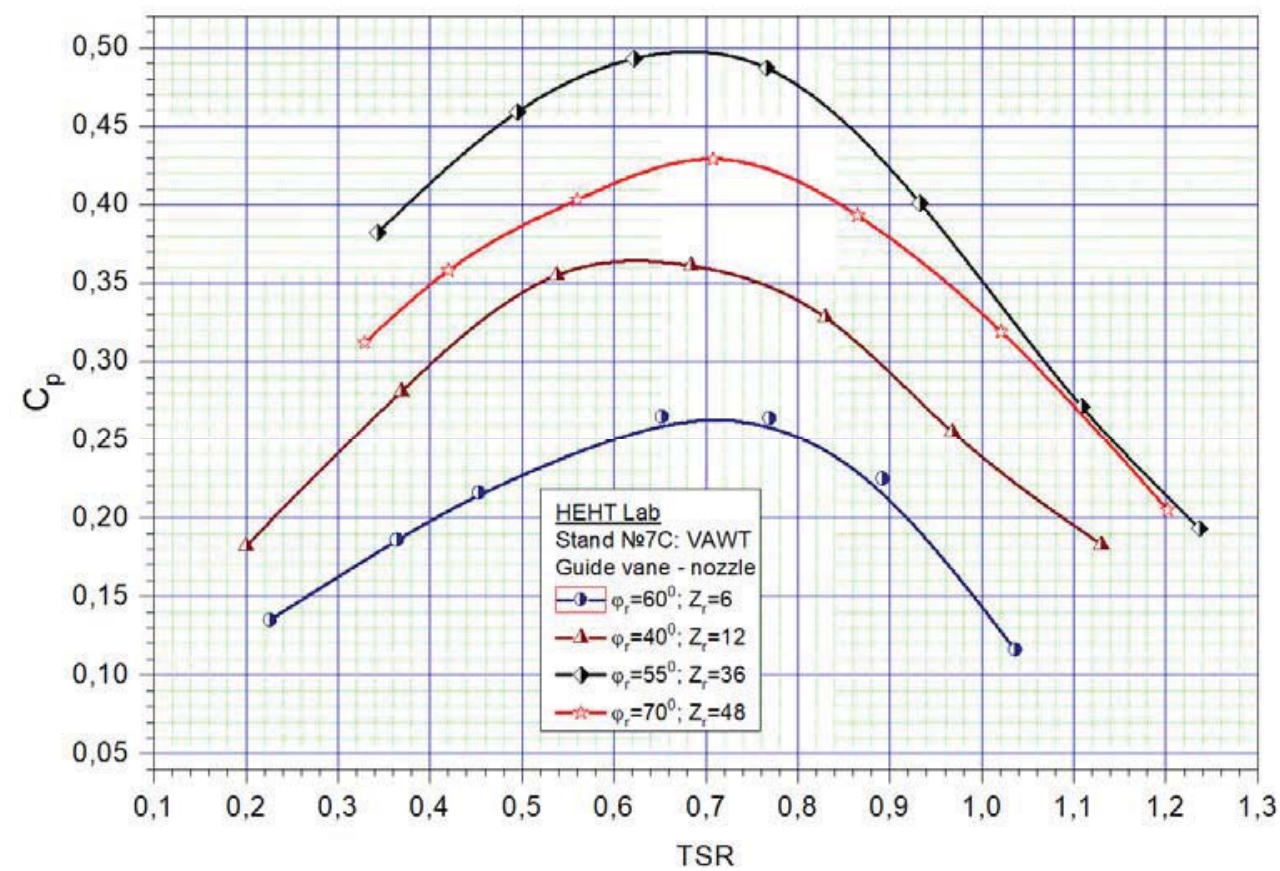

Fig. 3. Performance characteristics 


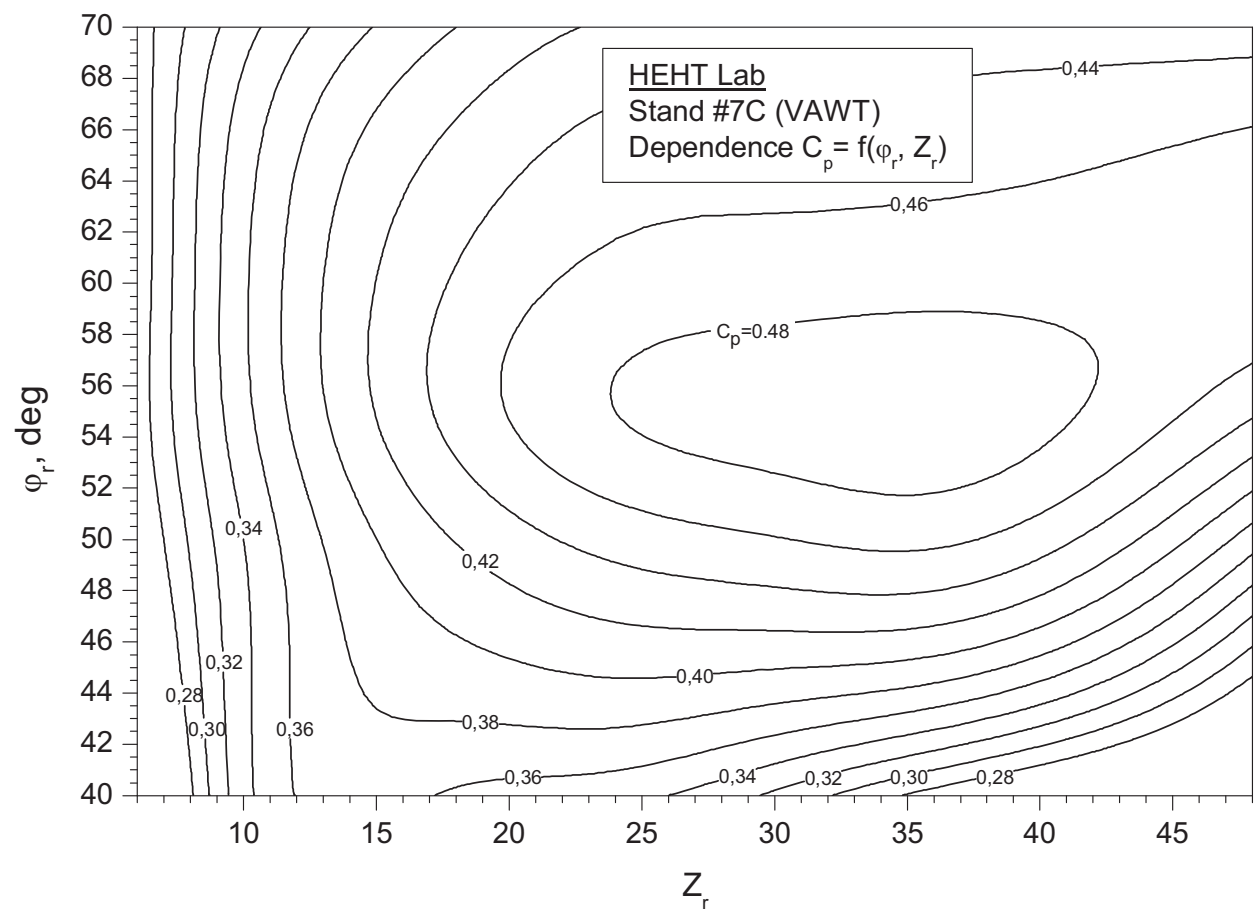

Fig. 4. Generalized characteristic

\section{Analysis of the results}

The analysis of the results of the experimental studies leads to the following important conclusions:

A). The use of a guidance device type nozzle greatly improves the workflow of Darrieus VAWT. The results of the experimental studies show that the maximum values of the power coefficient $\left(\mathrm{c}_{\mathrm{p} \max } \approx 50 \%\right.$ ) increase significantly compared to the data from the test of the same turbine with a cylindrical guiding vane and in the absence of a guiding apparatus. The main reasons for this can be formulated as following:

- Directing the flow only to the working blades in the active zone matching kinematic flow parameters in the nozzle outlet cross section and the runner's outlet section.

- Using the possibility of a double interaction of the flow with the blades, with appropriate angles of attack.

B). The number of the blades has a noticeable effect on the values. Fig.5 shows the dependence $c_{p \max }=f\left(Z_{r}\right)$ for the optimal value of the pitch angle $\left(\varphi_{r}=55^{\circ}\right)$. It is built based on the data from the generalized characteristics (Fig.4).

C). The pitch angle of the blades also significantly affects the efficiency of the work process in this case (a guiding nozzle). This is easily explained since the nozzle forms a constant-angled flow that corresponds to a well-defined value of the pitch angle of the blades.

As this angle increases and decreases, the impact losses in the work area of the runner increase, especially with the specific geometry of the blades. It can be assumed that the use of profiled blades with a larger radius in the inlet will increase the efficiency of the workflow at the lower and higher values (away from the optimum) of the pitch angle. 


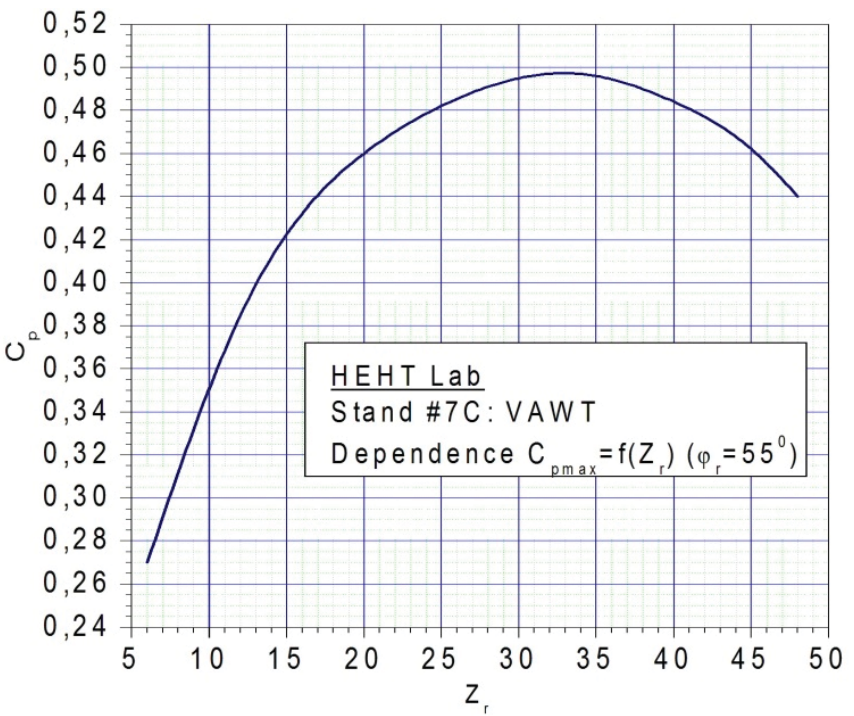

Fig. 5. Dependence $c_{p \max }=f\left(Z_{r}\right)$

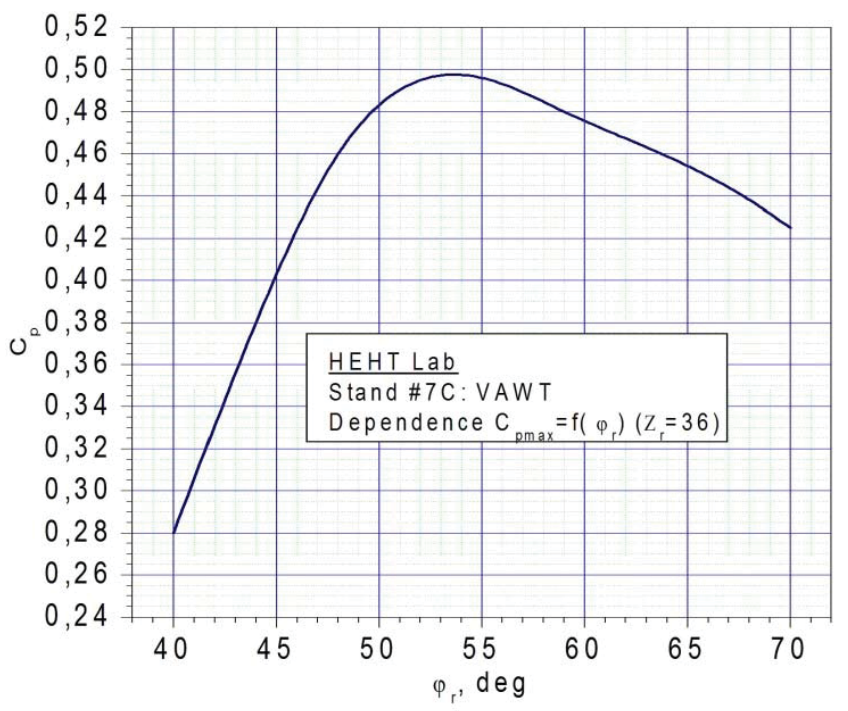

Fig. 6. Dependence $c_{p \max }=f\left(\varphi_{r}\right)$
Fig.6 shows the dependence $c_{p \max }=f\left(\varphi_{r}\right)$ of the optimum value of the number of the blades $\mathrm{Z}_{\mathrm{r}}=33$ according of the summary data.

D). A numerical study of the flow in the nozzle and the runner for some operating regimes has been made. The far field velocity is the same as in the experiments $(5.9 \mathrm{~m} / \mathrm{s})$ and the operating pressure corresponds to the atmospheric pressure in the lab $(980 \mathrm{hPa})$. Komega SST turbulence model has been used. Fig.7 shows streamlines of the velocity distribution for a runner with 36 blades and pitch angle $55^{\circ}$ at the optimal operating regime. Fig. 8 shows a runner with 12 blades, pitch angle $40^{\circ}$ at the optimal operating regime.

With a 12-blade runner, there is a detachment of the flow even at the inlet of the blades, due to the improper pitch angle and this impairs the operating characteristics. In addition, an attack of the blades from the inactive zone in their back part is detected, which is a prerequisite for the occurrence of a resistance moment.

It is important to note that in the synthesis of the geometry of the blades it is necessary to take into account the interaction with the flow during the second passage through the blade system [6].

E). According to the result from experimental studies, the optimal values of the number of blades and their angle of placement are respectively $\mathrm{Z}_{\mathrm{r}}=33$ and $\varphi_{\mathrm{r}}=53.5^{0}$. 
F). It should be considered that this turbine arrangement requires the construction of a device for directing the nozzle in the direction of the air flow.

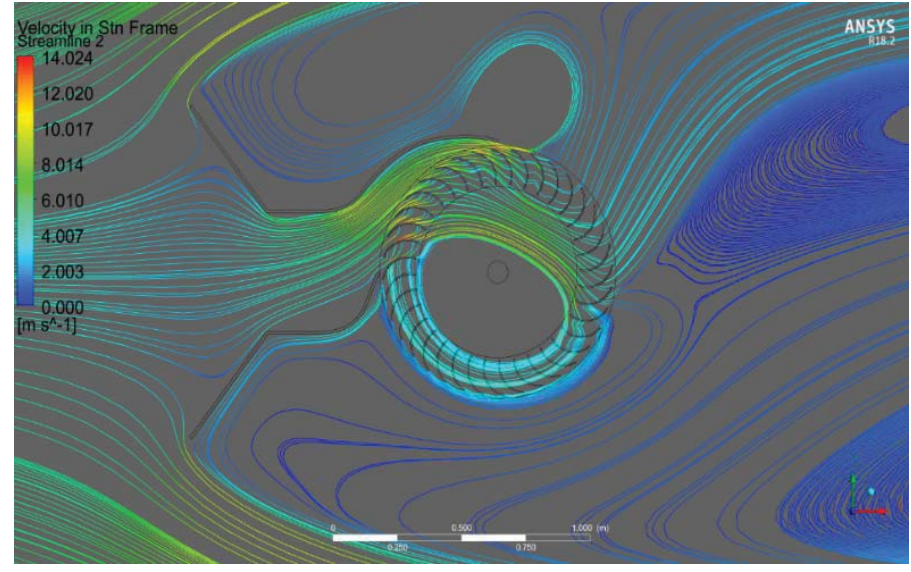

Fig. 7. Streamlines of the velocity distribution $\left(Z_{r}=36 ; \varphi_{r}=55^{\circ}\right)$

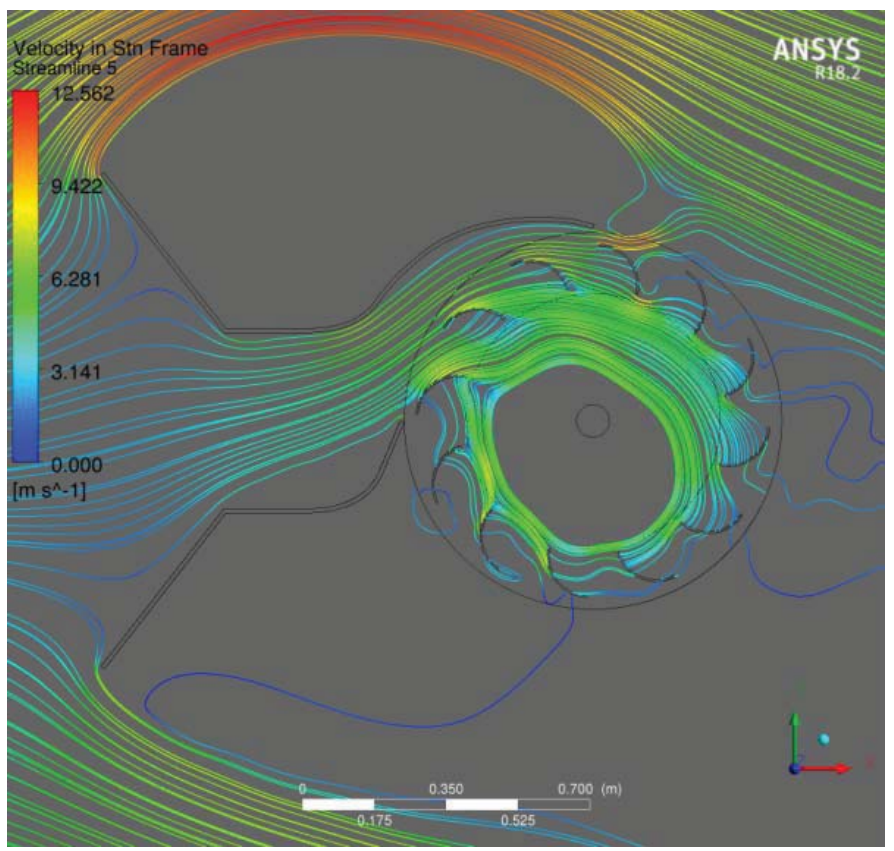

Fig. 8. Streamlines of the velocity distribution $\left(Z_{r}=12 ; \varphi_{r}=40^{\circ}\right)$

\section{Conclusion}

The main results of this study are expressed as following:

1. An experimental study of a model Darius VAWT with a guiding apparatus - nozzle has been conducted. 
2. Many operating regimes have been investigated, with different runner geometry (different number of blades and pitch angles) and based on this a generalized characteristic $c_{\mathrm{p} \max }=\mathrm{f}\left(\varphi_{\mathrm{r}}, Z_{\mathrm{r}}\right)$ has been created.

3. The results of the studies show that the optimal values of the number of working blades and their pitch angle are $Z_{r}=33$ and $\varphi_{r}=53.5^{\circ}$

4. On the basis of a numerical study of the flow of the blade systems of the guiding apparatus and runner, the reasons for the differences in the characteristics of the VAWT have been analyzed.

5. The results of the pilot studies lead to the conclusion that using a nozzle for a Darrieus VAWT (especially with a higher power) is justified (from an energy and investment point of view), regardless of the complications which it imposes in terms of construction and operation. The efficiency of the studied turbine is at least twice as high as that of the VAWT, made according to a classical scheme and even with a cylindrical guide device $[9,10]$.

\section{References}

1. V. Obretenov, Ts. Tsalov, P. Nikolov. Investigation of the vertical axis wind turbine with guide apparatus. Proceedings of the Scientific Conference EMF`2016, vol. II, pp. 69-77, Sozopol, (2016), in Bulgarian.

2. K. Pankaj, A.Saran, A.Ansar. Optimisation of performance of multi bladed vertical axis wind turbine by using a nozzle. IJETAE, ISSN 2250-2459, Volume 4, Special Issue 1, February (2014).

3. L. Rus. Experimental study on the increase of the efficiency of vertical axis wind turbines by equipping them with wind concentrators. JSE, vol. 3, no. 1, March, (2012).

4. V. Obretenov, Ts. Tsalov. The new hydraulic laboratory at the Technical University of Sofia. Proceedings of the IX international scientific and technical conference „Hydraulic machines, hydraulic drives and hydro- and pneumatic automation. Current status and development prospects“, pp. 79-87, St. Petersburg, (2016).

5. V. Obretenov, R.Iliev. A new model vertical axis wind turbine. Proceedings of the Scientific Conference EMF`2018, vol. II, pp. 288-295, Sozopol, (2018), in Bulgarian.

6. V. Obretenov. Optimization of cross-flow water turbine. Proceedings of the 26th Israel conference on mechanical engineering, pp. 535 - 537. Technion city, Haifa, Israel, (1996).

7. V. Obretenov, Ts.Tsalov. Guide for laboratory exercises in hydro and wind energy. (machinery and equipment). "Publishing house of the University of Ruse", (2017), in Bulgarian.

8. B. Shahizare, N.Nazri, N.Ghazali, W.Chong, S.Tabatabaeikia and N.Izadyar. Investigation of the optimal omni-direction-guide-vane design for vertical axis wind turbines based on unsteady flow CFD simulation. Energies, 9, pp.146 (2016).

9. A. Rahman, N. Yahaya, R. Bahsan, U. Ahmad. Energy harvesting from cooling tower by vertical axis wind turbine (VAWT). Jurnal Tecknologi (Sciences \& Engineering) No76, pp. 37-41, 2015.

10. D. Wibowoa, D. Tjahjanab, B. Santoso, M. Situmorang. Study of Turbine and Guide Vanes Integration to Enhance the Performance of Cross flow Vertical Axis Wind Turbine. AIP Conference Proceedings 1931, 030043, pp. 030043-4, (2018). 